\title{
Probability-theoretic approach to modeling a respirator on chemically bound oxygen
}

- Ekhilevskiy, S.G.,

- Golubeva, O.V.,

- Potapenko, E.P.

- View Correspondence (jump link)

- Polotsk State University, Novopolotsk, Belarus

\section{Краткое описание}

At present, the main prospects for improving the insulating means of respiratory protection are related to the chemical method of oxygen reservation. The arguments in favor of this choice are the high density of oxygen packaging and its self-regulating supply, depending on the physical activity of the person. Usually, the working process in devices on chemically bound oxygen is modeled using mathematical physics methods that solve the so-called sorption dynamics problem. As a result, under given boundary and initial conditions, the concentration of $\mathrm{CO}_{2}$ mole-cules in the regenerative cartridge turns out to be a deterministic function of time and coordinates. However, the coordinate of the elementary act of sorption is essentially a random variable. The law of its distribution evolves as the absorbing resource of the regenerative cartridge is consumed. Taking into account the above, a probability-theoretic approach to modeling the working process of an insulating breathing apparatus based on chemically bound oxygen was developed. The approach is based on the description by probability theory methods of the random coordinate of the elementary act of chemosorption of a $\mathrm{CO}_{2}$ molecule by potassium peroxide granules and the random lifetime of this molecule in the regenerative cartridge of the respiratory apparatus. The evolution of the initial and central statistical moments of these values is es-tablished. The symmetry of their probability density with respect to the permutation of dimensionless arguments is shown, which are the time and distance from the entrance to the regenerative cartridge to the considered layer of chemisorbent. The presence of symmetry increases the speed of numerical experiments by one or two orders of magnitude. Gaussian asymptotics of the process at long times and corrections to it by inverse degrees of dispersion due to asymmetries and excesses of different orders are revealed. This further increases the speed of numerical experiments in computer simulation of the working process of an insulating respirator on chemically bound oxygen. (C) 2020, STC Industrial Safety CJSC. All rights reserved. 


\section{Актуальность темы SciVal}

Tема: Hydrogen Cyanide | Activated Carbon | Respiratory Protective Devices

\section{Ключевые слова автора}

Air regenerationAsymptotics of the respirator working processChemically bound oxygenChemisorption actFormalism methodlsolation breathing apparatusOxygen-containing productProbabilistic-theoretical approach

- ISSN: 04092961

- CODEN: BZTPA

- Тип источника: Journal

- Язык оригинала: Russian

- DOI: $10.24000 / 0409-2961-2020-10-7-15$

- Тип документа: Article

- Издатель: STC Industrial Safety CJSC

https://www.scopus.com/record/display.uri?eid=2-s2.0-85094894865\&doi=10.24000\%2f0409-29612020-10-7-15\&origin=inward\&txGid=0c9adce096ff9c518ef435aefc8bfe34

https://doi.org/10.24000/0409-2961-2020-10-7-15 